\title{
Functional outcome of traumatic paraplegia and paraparesis patients treated with pedicle screw stabilization with decompression
}

\author{
Arif P. K. ${ }^{1}$, Tigy Thomas Jacob ${ }^{2 *}$ \\ ${ }^{1}$ Senior Resident, ${ }^{2}$ Department of Orthopedics, Government Medical College, Kottayam, Kerala, India \\ Received: 22 December 2020 \\ Revised: 30 January 2021 \\ Accepted: 30 January 2021 \\ *Correspondence: \\ Dr. Tigy Thomas Jacob, \\ E-mail: drtigy67@gmail.com
}

Copyright: (C) the author(s), publisher and licensee Medip Academy. This is an open-access article distributed under the terms of the Creative Commons Attribution Non-Commercial License, which permits unrestricted non-commercial use, distribution, and reproduction in any medium, provided the original work is properly cited.

\begin{abstract}
Background: In this study, unstable thoracolumbar spine fractures with neurological deficit fixed with Moss Miami pedicle screw and decompression were followed up for neurological improvement (sensory and motor functions). Patients were admitted in the department of Orthopaedics, Government medical college, Kottayam from November 2016 to October 2017.

Methods: In this observational study, 96 patients (aged 17 to 60 years) are followed up. The preoperative neurological status and post-operative recovery are follow-up at 1, 3 and 6 months and graded by Frankel's grading. Change from Frankel's grade A OR B to Frankel grade C, D OR E was said to be improved neurologically.

Results: $87.3 \%$ males and $12.7 \%$ females with $58.3 \%$ patients having fall from height sustained wedge compression fractures $(49.1 \%)$, burst fractures $(46.8 \%)$ and fracture dislocations $(4.1 \%)$. vertebra fractured were L1-31.4\%, T12$22.9 \%$ and L2-19.7\%. Complete paralysis was $44.8 \%$ and $55.2 \%$ incomplete. At 6 months $75 \%$ patients showed improvement and $25 \%$ patients showed nil. $95.5 \%$ patients (18-30 years) showed improvement and only 50\% (51-60 years). Incomplete neurological deficit showed significant improvement (100\%) compared to patients with complete paralysis (44.2\%). Preoperative Frankel score has significant relationship with final neurological (44\% of patients with Frankel A and $100 \%$ with Frankel D.

Conclusions: Moss Miami pedicle screw stabilization with decompression is an effective surgical technique in maintaining stability of spine in traumatic paraplegia and paraparesis patients and there is significant improvement in neurological status.
\end{abstract}

Keywords: Decompression, Frankel score, Moss Miami pedicle screw stabilization, Neurological deficit

\section{INTRODUCTION}

Trauma a grave injuries cause morbidity and disability to the patient who may be confined to bed for his life. It affects young adult bread earners and economic and emotional burden to the family.

Thoracolumbar fractures occur from trauma, fall from height, road traffic accidents and crush injuries. ${ }^{1}$ They result from vertical compression to the slightly flexed spine, but a rotational or shear component or some extension force can cause a different fracture pattern.
Twenty percent of them are associated with neurological deficits, a significant cause of morbidity and mortality.

In the past few decades in spite of advancements in diagnostic imaging techniques, more stable fixation devices, use of steroids to reduce the secondary injury to the neural elements and intra-operative monitoring these fractures still pose a challenge and controversy. Orthopedic department of Government Medical College Hospital, Kottayam with 100-150 yearly turn out provides an ideal setup for any research in this field. Even though neurological improvement is independent of the treatment 
modality, surgical decompression point at theoretical advantages of surgery in improving neurological deficits. Lately, consensus is evolving around the world for stabilization of spine with fusion and instrumentation in unstable fractures.

A short segment posterior instrumentation with pedicle screw system in spinal injuries achieves a reasonable stability since the pedicle screw and rod system provides a three column fixation in stabilizing the injured spinal column incorporating fewer motion segment in the fusion. $^{2-4}$ Surgical decompression and posterior instrumented fusion in spinal injuries enables an ambulant painless patient with a fair chance of neurological recovery. ${ }^{5}$ It increases longevity executes better nursing care to paraplegics and decreases the morbidity due to prolonged recumbency. ${ }^{6}$

Surgical treatment can be by anterior, familiar posterior, lateral or anteroposterior approaches. Historically, Harrington hook-rod construct or its modifications have been extensively studied. ${ }^{4}$ Their main disadvantage is it spans at least 5-6 spinal segments. So newer options, especially pedicle screw plate or rod constructs which need shorter segment immobilization have gained popularity.

\section{Objective}

To assess the neurological improvement in case of traumatic paraplegia/para paresis patients, after Moss Miami pedicle screw stabilization with decompression using Frankel scoring.

\section{METHODS}

\section{Ethical Concern}

Ethical approval obtained from the institutional ethical committee.

\section{Study design}

It was a prospective study.

\section{Study setting}

Study was conducted at Department of Orthopaedics, Government Medical College, Kottayam.

\section{Study population}

A total of 96 patients were involved in the study.

\section{Sample size}

Case satisfying inclusion criteria admitted during study period of January 2016-June 2017 were included after taking consent were analyzed clinically and radiologically all the patient selected from the study were examined according to protocol. Associated injury was noted and clinical, laboratory investigations carried out in order to get fitness for surgery.

\section{Sample size calculation}

$$
\mathrm{n}=\frac{4 \times p \times q}{d^{2}}
$$

$\mathrm{p}=$ prevalence of improved cases (40)

$q=100-p$

$\mathrm{d}=10$

$\mathrm{n}=\frac{4 \times 40 \times 60}{100}$

A prospective study of 96 cases was planned.

\section{Inclusion criteria}

Thoracic lumbar fractures with neurological deficit. Vertebral fractures below the level of D9 with neurological deficit. Single level vertebral fractures.

\section{Exclusion criteria}

Moribund patients. Significant osteopenia. Stable fractures of thoracic lumbar spine. Cervical spine injuries.

\section{Statistical analysis}

The data were expressed using descriptive statistics such as mean, standard deviation, frequency, percentage, etc. Comparison of continuous variable between groups, was done using independent sample ' $\mathrm{t}$ ' test/ANOVA. Categorical variables were analysed by Chi square test for their significant association. $\mathrm{P}$ value $<0.05$ were considered statistically significant. Following observations were made from the statistical data obtained from our study.

\section{Study procedure}

All the cases satisfying inclusion criteria, admitted in department of orthopedics Kottayam Medical college Hospital are assessed and investigated. Data was collected after taking consent. Data include age, sex, time from injury to hospitalization, initial neurological status as per Frankel score, MRI findings (if taken), surgery performed. Post-operative course and neurological status at the time of discharge, follow up.

Follow up was done to assess the Frankel score by clinical examination at the immediate post op, 1 month, 3 month, 6 month after surgery. Any change from Frankel score A or B to score C, D or E was considered as improvement. Patient lost to follow up were not studied for outcome analysis. SPSS 16 was used for statistical analysis. 
Table 1: Acute spinal code injury-Frankel classification grading system.

\begin{tabular}{|c|c|}
\hline Grade A & $\begin{array}{l}\text { Complete neurological injury-no motor } \\
\text { or sensory function clinically detected } \\
\text { below the level of injury }\end{array}$ \\
\hline Grade B & $\begin{array}{l}\text { Preserved sensation only- no motor } \\
\text { function clinically detected below the level } \\
\text { of injury; sensory function remains below } \\
\text { the level of injury but may include only } \\
\text { partial function (sacral sparing qualifies as } \\
\text { preserved sensation }\end{array}$ \\
\hline Grade C & $\begin{array}{l}\text { Preserved motor non-functional- some } \\
\text { motor function observed below the level of } \\
\text { the injury, but is of no practical use to the } \\
\text { patient }\end{array}$ \\
\hline Grade D & $\begin{array}{l}\text { Preserved motor function- useful motor } \\
\text { function below the level of injury; patient } \\
\text { can move lower limbs and walk with or } \\
\text { without aid, but does not have a normal } \\
\text { gait or strength in al motor groups }\end{array}$ \\
\hline Grade E & $\begin{array}{l}\text { Normal motor -no clinically detected } \\
\text { abnormality in motor or sensory function } \\
\text { with normal sphincter function; abnormal } \\
\text { reflexes and subjective sensory } \\
\text { abnormalities may be present }\end{array}$ \\
\hline
\end{tabular}

\section{RESULTS}

In this series $83(87.3 \%)$ patients were males and 13 $(12.7 \%)$ patients were females. $23(23.9 \%)$ patients were between the age group of 18-30. $22(22.9 \%)$ patients were between the age group of 31-40. There were 25 (26.1\%) patients between age group of $41-50$ and $26(27.1 \%)$ patients between 51-60 years of age group.

Table 2: Distribution of study population according to gender, age, mode of injury and type of injury.

\begin{tabular}{|lll|}
\hline Characteristics & No. of patients & Percent \\
\hline Gender & & \\
\hline Males & 83 & 87.3 \\
\hline Females & 13 & 12.7 \\
\hline Age & & \\
\hline $18-30$ & 23 & 23.9 \\
\hline $31-40$ & 22 & 22.9 \\
\hline $41-50$ & 25 & 26.1 \\
\hline $51-60$ & 26 & 27.1 \\
\hline Mode of injury & & \\
\hline Fall from height & 56 & 58.3 \\
\hline RTA & 37 & 38.5 \\
\hline $\begin{array}{l}\text { Fall of heavy object over } \\
\text { back }\end{array}$ & 3 & 3.2 \\
\hline Type of injury & & \\
\hline Wedge compression fracture & 47 & 49.1 \\
\hline Burst fracture & 45 & 4.1 \\
\hline Fracture dislocation & 4 & \\
\hline
\end{tabular}

In this study, 56 patients (58.3\%) had fall from height, 37 patients $(38.5 \%)$ had RTA and 3 patients $(3.2 \%)$ had history of fall of heavy object over back.

In this study, there were 47 patients $(49.1 \%)$ with wedge compression fracture vertebrae, 45 patients $(46.8 \%)$ with burst fracture and 4 patients $(4.1 \%)$ with fracture dislocation vertebra.

Table 3: Level of injury.

\begin{tabular}{|lll|}
\hline Level of injury & No. of patients & Percentage \\
\hline T10 & 3 & 3.1 \\
\hline T11 & 12 & 12.5 \\
\hline T12 & 22 & 22.9 \\
\hline L1 & 30 & 31.4 \\
\hline L2 & 19 & 19.7 \\
\hline L3 & 9 & 9.3 \\
\hline L4 & 1 & 1.1 \\
\hline Total & 96 & 100.0 \\
\hline
\end{tabular}

In this study, 3 patients $(3.1 \%)$ had fracture vertebra at the level of T10, 12 patients $(12.5 \%)$ at the level of T11 vertebra, 22 patients $(22.9 \%)$ at the level of T12 vertebra. 30 patients $(31.4 \%)$ had fracture at the level of L1 vertebra, 19 patients $(19.7 \%)$ at the level of L2 vertebra, 9 patients $(9.3 \%)$ at the level of L3 vertebra and 1 patient (1.1\%) at the level of L4 vertebra.

Table 4: Distribution of study sample according to mode of injury and type of injury.

\begin{tabular}{|lllll|}
\hline \multirow{5}{*}{$\begin{array}{l}\text { Mode of } \\
\text { injury }\end{array}$} & $\begin{array}{l}\text { Type of injury } \\
\begin{array}{l}\text { Wedge } \\
\text { compression } \\
\text { fracture }\end{array}\end{array}$ & $\begin{array}{l}\text { Burst } \\
\text { fracture }\end{array}$ & $\begin{array}{l}\text { Fracture } \\
\text { dislocation }\end{array}$ & Total \\
\hline $\begin{array}{l}\text { Fall from } \\
\text { height }\end{array}$ & 31 & 24 & 1 & 57 \\
\hline RTA & $56.1 \%$ & $42.1 \%$ & $1.7 \%$ & $100.0 \%$ \\
\cline { 2 - 5 } & 45 & 19 & 3 & 37 \\
\hline $\begin{array}{l}\text { Fall of } \\
\text { heavy } \\
\text { object } \\
\text { over } \\
\text { back }\end{array}$ & 1 & $51.4 \%$ & $8.1 \%$ & $100.0 \%$ \\
\hline Total & $33.3 \%$ & 2 & 0 & 3 \\
\hline
\end{tabular}

In patients with history of fall from height, 31 patients $(56.1 \%)$ sustained wedge compression fracture vertebra, 24 patients sustained $(42.1 \%)$ burst fracture and 1 patient $(1.7 \%)$ sustained fracture dislocation. In patients with history of RTA, 15 patients $(40.5 \%)$ sustained wedge Compression fracture vertebra, 19 patients sustained (51.4\%) burst fracture and 3 patients $(8.1 \%)$ sustained fracture dislocation. In patients with history of fall of heavy object over back, 1 patient (33.3\%) sustained wedge compression fracture vertebra, 2 patients sustained 
(66.7\%) burst fracture and no patients sustained fracture dislocation.

Table 5: Distribution of study sample according to presence of neurological deficit on admission.

\begin{tabular}{|lll|}
\hline $\begin{array}{l}\text { Neurological deficit } \\
\text { on admission }\end{array}$ & $\begin{array}{l}\text { No. of } \\
\text { patients }\end{array}$ & Percentage \\
\hline Complete & 43 & 44.8 \\
\hline Incomplete & 53 & 55.2 \\
\hline Total & 96 & 100.0 \\
\hline
\end{tabular}

On admission to this hospital, 43 patients (44.8\%) had complete paralysis and 53 patients $(55.2 \%)$ had incomplete neurological deficit.

\section{Factors associated with neurological deficit on} admission

In this study, in patients with history of fall from height 26 patients $(46.5 \%)$ had complete neurological deficit, 30 patients $(53.5 \%)$ had incomplete neurological deficit. In patients with history of RTA 17 patients $(45.9 \%)$ had complete neurological deficit, 20 patients $(54.1 \%)$ had incomplete neurological deficit. In patients with history of fall of heavy object over back 17 patients (45.9\%) had complete neurological deficit, 20 patients $(54.1 \%)$ had incomplete neurological deficit.

Table 6: Distribution of study sample according to mode of injury and neurological deficit on admission.

\begin{tabular}{|llll|}
\hline \multirow{2}{*}{ Mode of injury } & \multicolumn{2}{l}{ Neurological deficit } & Total \\
& Complete & Incomplete & \\
\hline \multirow{2}{*}{ Fall from height } & 26 & 30 & 56 \\
\cline { 2 - 4 } & $46.5 \%$ & $53.5 \%$ & $100.0 \%$ \\
\hline \multirow{2}{*}{ RTA } & 17 & 20 & 37 \\
\hline Fall of heavy & $45.9 \%$ & $54.1 \%$ & $100.0 \%$ \\
\hline object over back & 0 & 3 & 3 \\
\hline Total & $0.0 \%$ & $100.0 \%$ & $100.0 \%$ \\
\hline
\end{tabular}

Chi square: 2.577 ; $p$ value: 0.276 (not significant)

Inference: There was no significant association between mode of injury and neurological deficit on admission.

Table 7: Distribution of study sample according to lag period.

\begin{tabular}{|lll|}
\hline Lag period & No. of patients & Percentage \\
\hline Within one week & 40 & 41.7 \\
\hline 1-2 weeks & 52 & 54.2 \\
\hline More than 2 weeks & 4 & 4.1 \\
\hline Total & 96 & 100.0 \\
\hline
\end{tabular}

In this study, out of 96 patients surgery was done for 40 patients $(41.7 \%)$ within a week after the injury. Between
1-2 weeks in 52 patients $(54.2 \%)$ and after 2 weeks in 4 patients $(4.1 \%)$.

\section{Factors associated with final neurological outcome}

Between age group of $18-30$ years, $95.5 \%$ of the patients showed improvement in neurological status after the surgery. Between age group of 31-40 years, $90.9 \%$ of the patients showed improvement in neurological status after the surgery. Between age group of $41-50$ years, $68 \%$ of the patients showed improvement in neurological status after the surgery. Between age group of 51-60 years, only 50\% of the patients showed improvement in neurological status after the surgery.

Table 8: Distribution of study sample according to age and final neurological outcome.

\begin{tabular}{|llll|}
\hline $\begin{array}{l}\text { Age group } \\
\text { (in years) }\end{array}$ & $\begin{array}{l}\text { Final neurological outcome } \\
\text { Improved }\end{array}$ & Not improved & Total \\
\hline \multirow{2}{*}{$\mathbf{1 8 - 3 0}$} & 22 & 1 & 23 \\
\cline { 2 - 4 } & $95.5 \%$ & $4.5 \%$ & $100.0 \%$ \\
\hline \multirow{2}{*}{$\mathbf{3 1 - 4 0}$} & 20 & 2 & 22 \\
\cline { 2 - 4 } & $90.9 \%$ & $9.1 \%$ & $100.0 \%$ \\
\hline \multirow{2}{*}{$\mathbf{4 1 - 5 0}$} & 17 & 8 & 25 \\
\hline \multirow{2}{*}{$\mathbf{5 1 - 6 0}$} & $68.0 \%$ & $32.0 \%$ & $100.0 \%$ \\
\hline \multirow{2}{*}{ Total } & 13 & 13 & 26 \\
\hline & $50.0 \%$ & $50.0 \%$ & $100.0 \%$ \\
\hline & 72 & 24 & 96 \\
\hline
\end{tabular}

Chi square: 17.076 ; $\mathrm{p}$ value: 0.001 (significant)

Inference: There was significant association between age of the patient and final neurological outcome postoperatively.

Table 9: Distribution of study sample according to lag period and final neurological outcome.

\begin{tabular}{|c|c|c|c|}
\hline \multirow{2}{*}{ Lag period } & \multicolumn{2}{|c|}{ Final neurological outcome } & \multirow{2}{*}{ Total } \\
\hline & Improved & Not improved & \\
\hline \multirow{2}{*}{$\begin{array}{l}\text { Within } 1 \\
\text { week }\end{array}$} & 34 & 6 & 40 \\
\hline & $85 \%$ & $15 \%$ & $100.0 \%$ \\
\hline \multirow{2}{*}{$\begin{array}{l}\text { Between 1-2 } \\
\text { weeks }\end{array}$} & 36 & 16 & 52 \\
\hline & $69.2 \%$ & $30.8 \%$ & $100.0 \%$ \\
\hline \multirow{2}{*}{$\begin{array}{l}\text { More than } 2 \\
\text { weeks }\end{array}$} & 2 & 2 & 4 \\
\hline & $50.0 \%$ & $50.0 \%$ & $100.0 \%$ \\
\hline \multirow{2}{*}{ Total } & 72 & 24 & 96 \\
\hline & $75 \%$ & $25 \%$ & $100.0 \%$ \\
\hline
\end{tabular}

Chi square: 4.147 ; $\mathrm{p}$ value: 0.126 (not significant)

Inference: There was no significant association between lag period (time period between injury and surgery) and final neurological outcome.

Out of 40 patients whose surgery was done within a week after the injury, 34 patients $(85 \%)$ showed improvement in neurological status. Out of 52 patients whose surgery was done between 1-2 weeks after the injury, 36 patients 
(69.2\%) showed improvement in neurological status. Out of 4 patients whose surgery was done within a week after the injury, 2 patients $(50 \%)$ showed improvement in neurological status.

Table 10: Distribution of study sample according to pre-operative Frankel score and final neurological outcome.

\begin{tabular}{|llll|}
\hline \multirow{2}{*}{$\begin{array}{l}\text { Pre-op } \\
\text { Frankel score }\end{array}$} & \multicolumn{2}{l}{$\begin{array}{l}\text { Final neurological } \\
\text { outcome } \\
\text { Improved }\end{array}$} & Not improved \\
\hline \multirow{2}{*}{ A } & 11 & 14 & 25 \\
\cline { 2 - 4 } & $44.0 \%$ & $56.0 \%$ & $100.0 \%$ \\
\hline \multirow{2}{*}{ B } & 18 & 10 & 28 \\
\hline \multirow{2}{*}{ C } & $64.3 \%$ & $35.7 \%$ & $100.0 \%$ \\
\hline \multirow{2}{*}{ D } & 40 & 0 & 40 \\
\hline \multirow{2}{*}{ Total } & $100.0 \%$ & $.0 \%$ & $100.0 \%$ \\
\hline & 3 & 0 & 3 \\
\hline
\end{tabular}

Chi square: 28.326 ; $\mathrm{p}$ value: 0.001 (significant)

Inference: There was significant association between preoperative Frankel grade and final neurological outcome.

Out of 25 patients with pre-op Frankel grade A, 11 patients (44\%) showed improvement in final neurological status. Out of 28 patients with pre-op Frankel grade B, 18 patients $(64.3 \%)$ showed improvement in final neurologic status. Out of 40 patients with pre-op Frankel grade C, all patients (100\%) showed improvement in final neurologic status. Out of 3 patients with pre-op Frankel grade D, all patients $(100 \%)$ showed improvement in final neurologic status.

\section{DISCUSSION}

Dorsolumbar spinal injury with neurological deficit is an overwhelming crisis leading to considerable morbidity and mortality. Debate exists over the exact modality of treatment and timing of intervention. ${ }^{7}$ Whether to use: 1 ) Anterior decompression and fusion- Anterior instrumentation. 2) Posterior decompression and fusion Posterior instrumentation. 3) Combined. 4) Early or late surgical intervention is helpful.

All aspects of management aims at preventing secondary injury to the spinal cord of which mechanical compression is one of the most important reversible factor.

Non-operative care avoids anaesthetic risk and morbidity of surgery but increases the risks of prolonged recumbency and hospital stay. The current surgical management corrects the deformity, enhances the neurological recovery, and allows early mobilization and return to work, with minimal complication. ${ }^{8,9}$
With improved investigations and advanced stabilization systems and intra operative monitoring of cord function the outlook for patients with thoracolumbar fractures with neurological deficits has improved and can be enhanced if an optimum environment for neurological recovery is provided. ${ }^{10}$

In our study all the cases underwent posterior decompression, short segment stabilization with pedicle screws. This was performed within 3 weeks of injury with an average of 10 days. In most of studies it was found that males in the age group of 20-40 years more commonly sustain spinal injuries. But in this study males of all age group 18-60 were almost equally undergone this injury.

They form a most important socioeconomic group. ${ }^{11}$ The most common mode of violence is an accidental fall from height, while vehicular accidents account for a few. When compared with primitive system like the ones which force the lamina apart or straighten the spine, the pedicle screw systems with large fixation screws implanted through the pedicle into the vertebral body are better systems biomechanically.

They are the only device which allows three column fixation of the vertebral column and in areas where the lamina have been removed. They provide excellent stability in fracture spine.

A short segment fixation with pedicle screw achieves reasonable stability. This is so because a pedicle screw achieves a three column fixation and proper stability than the other posterior systems that were used previously. The main advantage of short segment posterior instrumentation is that it preserve the motion segment resulting in less spinal stiffness and also avoiding flat back syndrome. ${ }^{12,13}$

McLain et al and McCormack et al reported that the use of short-segment posterior spinal instrumentation without restoration of the anterior column for the treatment of unstable thoracolumbar burst fractures has been associated with a high rate of early implant failure and progressive deformity. ${ }^{14-16}$

Short-segment pedicle screw fixation allows for spinal stabilization while simultaneously preserving as many motion segments as possible. ${ }^{17-20}$ When short-segment fixation was compared to long-segment fixation, the radiographic parameters were more favourable in the latter but the clinical outcome was the same for both methods. ${ }^{21,22}$

In our study all the cases underwent only posterior decompression, posterior stabilization. We had not done anterior procedures. Still they had good neurological recovery.

The maximum follow up in our study is 12 months. During their follow up we had not seen cases with implant related failure or with worsened neurological status and 
deformity. Patients whose MRI showing features of cord contusion had poor recovery.

Marco et al reported that the neurological function improved by at least one Frankel grade in $83 \%$ of the patients with complete neurological deficit in his study. ${ }^{14}$

But in our study $75 \%$ improvement in neurological function by one Frankel grade was observed in patients with complete neurological deficit.

The most important factor responsible for prognosis and neurological recovery is the neurological status at the time of injury. Surgical decompression and stabilization with fusion improves the neurological recovery especially in incomplete cord lesions. Out of 96 cases, all 53 cases with incomplete lesions have recovered well when compared to 43 complete lesions in our study. Another important factor for the post-operative improvement in our study was preop Frankel score. Patient with grade $\mathrm{C}$ and $\mathrm{D}$ improved drastically when compared to Frankel grade A and B. Patients belonged to younger age groups (18-30 and 3140) improved very well comparing the patients belonged to the age group of 41-50 and 51-60)

\section{CONCLUSION}

Early surgery had better outcome and rehabilitation. A short segment fixation with pedicle screw along with the orthotic appliances for a considerable period of time reduces the chances of implant failure and prevents further collapse of the injured vertebra and achieves a reasonable stability till the segment is fused.

Short segment posterior instrumentation preserves the motion segment, improves functional outcome and rehabilitate the patients with minimal surgical morbidity.

The enthusiasm of fixing and fusing the unstable spine is well rewarded with reduced fracture pain, making the patient to sit up and avoiding the complications of recumbency like pressure sore, urinary infections, deep vein thrombosis, pneumonitis and aids in neurological recovery especially in partial neurological deficit patients.

\section{ACKNOWLEDGEMENTS}

I express my thanks and gratitude to Dr. Tigy Thomas Jacob, Additional Professor, Orthopedics.

Funding: No funding sources

Conflict of interest: None declared

Ethical approval: The study was approved by the institutional ethics committee

\section{REFERENCES}

1. Chapman, MW, Szabo RM, Marder RA, Vince KG, Mann RA, Lane JM,et al Chapman's Orthopaedic
Surgery. 3rd edn. Lippincott Williams and Wilkins; 2001:3713-4.

2. Hwang JH, Modi HN, Yang JH, Kim SJ, Lee SH. Short segment pedicle screw fixation for unstable T11-L2 fractures: with or without fusion? A threeyear follow-up study. Acta Orthop Belg. 2009;75(6):822-7.

3. Jeffrey WP, Joel RL, Eldin EK, Robert WG. Successful short-segment instrumentation and fusion for thoracolumbar spine fractures a consecutive 4 1/2-year series. Spine. 2000;25:1157-69.

4. Butt MF, Farooq M, Mir B, Dhar AS, Hussain A, Mumtaz M. Management of unstable thoracolumbar spinal injuries by short segment spinal fixation. Int Orthop. 2007;31:259-64.

5. 1. Chapman, MW, Szabo RM, Marder RA, Vince KG, Mann RA, Lane JM,et al Chapman's Orthopaedic Surgery. 3rd edn. Lippincott Williams and Wilkins; 2001:3728.

6. Broom MJ, Jacobs RR. Current status of internal fixation of thoracolumbar fractures. J Orthop Trauma. 1989;3:148.

7. Lee SH. Short segment fixation for thoracolumbar fractures IJO. 2009;43(2):199.

8. Sasso RC, Costler HB. Posterior instrumentation and fusion for unstable fractures and fracture-dislocations of the thoracic and lumbar spine. Spine. 1993; 18:450-60.

9. Jacobs RR, Casey MP. Surgical management of thoracolumbar spinal injuries. Clin Orthop Relat Res. 1984;189:22-35.

10. Aebi M, Etter C, Kehl T. Stabilization of the lower thoracic and lumbar spine the internal spine skeletal fixation system. Indication, technique, and first results of treatment. Spine. 1987;12:544-51.

11. Gertzbein S. Scoliosis Research Society. Multicenter spine fracture study. Spine. 1992;17:528-40.

12. SH Lee et al: Short segment fixation for thoracolumbar fractures IJO April - June 2009 Vol 43 Issue 2 P 199.

13. Olerud S, Karlstrom G, Sjostrom L. Transpedicular fixation of thoracolumbar vertebral fractures. Clin Orthop Relat Res. 1988;227:44-51.

14. Marco RA, Kushwaha VP. Thoracolumbar burst fractures treated with posterior decompression and pedicle screw instrumentation supplemented with balloon-assisted vertebroplasty and calcium phosphate reconstruction. J Bone Joint Surg. 2009;91(1):20-8.

15. McLain RF, Sparling E, Benson DR. Early failure of short-segment pedicle instrumentation for thoracolumbar fractures. A preliminary report. J Bone Joint Surg Am. 1993;75:162-7.

16. McCormack T, Karaikovic E, Gaines RW. The load sharing classification of spine fractures. Spine. 1994;19:1741-4.

17. Dashti H, Lee HC, Karaikovic EE, Gaines Jr RW. Decision making in thoracolumbar fractures. Neurol India. 2005;53(4):534. 
18. Glaser JA, Estes WJ. Distal short segment fixation of thoracolumbar and lumbar injuries. Iowa Orthop J. 1998;(18):87-90.

19. Parker JW, Lane JR, Karaikovic EE, Gaines RW. Successful short-segment instrumentation and fusion for thoracolumbar spine fractures: a consecutive 41/2-year series. Spine. 2000;25(9):1157-70.

20. Sanderson PL, Fraser RD, Hall DJ, Cain CM, Osti OL, Potter GR. Short segment fixation of thoracolumbar burst fractures without fusion. Eur Spine J. 1999;8(6):495-500.
21. Lee SH. Short segment fixation for thoracolumbar fractures IJO. 2009;43(2):201.

22. Tezeren G, Kuru I. Posterior fixation of thoracolumbar burst fractures: Short segment pedicle fixation versus long segment instrumentation J Spinal Disord Tech. 2005;18:485-8.

Cite this article as: Arif PK, Jacob TT. Functional outcome of traumatic paraplegia and paraparesis patients treated with pedicle screw stabilization with decompression. Int J Res Orthop 2021;7:369-75. 